\title{
End of the Road for NERVA
}

by our Washington Correspondent

AFTER spending about $\$ 1,400$ million over sixteen years on the development of a large nuclear engine for space vehicles, the US Administration has finally decided to cut its losses and abandon the project. Much to the chagrin of some members of Congress and at least one Atomic Energy Commissioner, the Office of Management and Budget has stripped all funding for NERVA (Nuclear Engine for Rocket Vehicle Application) from the budgets of the Atomic Energy Commission and the National Aeronautics and Space Administration, and the project is probably doomed even if Congress follows past precedents and puts the money back into the budgets.

Officials of the Atomic Energy Commission last week appeared before the Joint Committee on Atomic Energy to discuss the Administration's decision to axe NERVA: most kept a stiff upper lip and insisted that the decision is justified, since there is no longer a requirement for such a large nuclear rocket. But Commissioner James T. Ramey, himself a past staff member of the Joint Committee, made no secret of his disappointment at the Administration's handling of NERVA: "For something like an additional $\$ 400$ million," he said, "we can proceed with confidence through a flight test and give the United States an unquestioned place of leadership in space." At the very least, Ramey suggested that the Joint Committee should vote $\$ 20$ million to keep the project ticking over.

Whether the Joint Committee will follow Ramey's advice is a moot point, and it is probably academic in any case. Last year there was no question that the committee would authorize the expenditure of more money for NERVA than the Administration requested, but precisely because this support for the project was thwarted by the Office of Management and Budget, the ground rules have changed and the Administration may well kill the project without too much of a fight.

What happened last year was that in spite of strong support for NERVA from both NASA and the AEC, the Office of Management and Budget sent to Congress a request only for sufficient funds to keep the project ticking over. The Joint Committee on Atomic Energy, the Senate Committee on Aeronautical and Space Sciences and the House Committee on Science and Astronautics all authorized sufficient expenditure to allow NERVA develop- ment to proceed at a pace, but OMB refused to spend all the money, and the project was wound down. This year, with strong pressure on NASA to keep its budget approximately constant over the next few years, NERVA got squeezed out completely and Congressional committees are aware that decisions have already been taken to reduce staff levels in the two chief NERVA contractors, so that no matter what funding is authorized for the project in 1973 it will probably not be spent by the Administration.

Designed to move large payloads from low Earth orbit into geosynchronous orbit, or further afield to the Moon and planets, NERVA is being killed chiefly because there is not sufficient requirement for such a large vehicle in the early 1980 s, when it would have been available. That, at least, was the argument put forward last week by David S. Gabriel, director of the Space Nuclear Systems Division of the AEC, in testimony before the Joint Committee on Atomic Energy. Gabriel assured the committee that the technology would not be lost, however, for if the need for NERVA arises in the future, it would be possible to build on the existing technology base and have a nuclear engine ready for flight testing in a comparatively short time.

But the chief benefit from the $\$ 1,400$ million spent on NERVA is likely to occur in the development of a much smaller nuclear engine for a spacecraft that will be capable of reaching the outermost planets in the 1980 s. When James T. Fletcher, administrator of NASA, announced the cancellation of the Grand Tour of the outer planets, he pointed out that NASA and the AEC had undertaken to develop a nuclear powered outer planets spacecraft so that the option of visiting the planets beyond Saturn is not completely foreclosed this century. Similarly, Gabriel said last week that NERVA technology will be invaluable in building the miniNERVA, as it has been dubbed. (The scaled down version would have a thrust of about $15,000 \mathrm{lb}$ compared with the $75,000 \mathrm{lb}$ thrust of NERVA.)

In spite of these assurances, however, it became clear last week that the Administration has not yet made a definite decision to develop a small nuclear engine. Gabriel said later in his testimony that such an engine is only one candidate for outer planetary missions, and that a study will soon be carried out to determine what sort of propulsion system will be developed for space missions in the 1980s. Systems under consideration include advanced chemical rockets, nuclear-electric and solar-electric propulsion and nuclear propulsion.

Of those four options, nuclear-electric is the least advanced, solar-electric would not be practical for outer planetary studies on the fringes of the solar system because the Sun's power would be too weak, and so the final decision may well boil down to a choice between advanced chemical and nuclear propulsion. As far as costs are concerned, Gabriel tentatively suggested that nuclear-electric, nuclear and advanced chemical propulsion would each cost about $\$ 400$ million to develop, while solar-electric technology may be available for an outlay of about $\$ 100$ million. To carry NERVA development through to completion, on the other hand, would cost about $\$ 500-600$ million. Gabriel told the committee that funding levels for the engine programme will undoubtedly increase from the level proposed in the 1973 budget, when various designs have been studied and a commitment is made to one type of engine.

One rather ironic aspect of the cancellation of NERVA is that development of the engine has been tied to development of the shuttle-because of the very slight danger of radioactive release from the engine, NERVA would only have been used outside the Earth's atmosphere and the thinking was, therefore, that it would have been launched from the shuttle. It would also have been a useful means for carrying heavy satellites from the low orbit of the shuttle to synchronous orbit or to the Moon for later lunar exploration. Now that the shuttle has been given the goahead (Congress willing), however, there is not enough money available for NERVA. As Gabriel said last week, NERVA needs the shuttle, but the shuttle does not need NERVA.

\section{MARIHUANA \\ Pot and Healith}

by our Washington Correspondent

THE possibility that smoking marihuana can be damaging to health has for long been the basis of exaggerated claims and counter claims as the debate over the drug's legal status has intensified in the United States. And, since any aspect of the drug always makes for good copy in the press, the American 